\title{
Prevalence and Management of Hypertension in the Inpatient Setting: A Systematic Review
}

CME Editor: Thomas E. Baudendistel, MD, FACP'

Authors: R. Neal Axon, MD, MSCR ${ }^{1,2}$, Laura Cousineau, MLS ${ }^{3}$, Brent M. Egan, MD¹

\begin{abstract}
'Department of Internal Medicine, Division of General Internal Medicine and Geriatrics, The Medical University of South Carolina, Charleston, South Carolina; ${ }^{2}$ The Ralph H. Johnson VAMC, Medical and Research Services, Charleston, South Carolina; ${ }^{3}$ MUSC Library and Education Center, Charleston, South Carolina.
\end{abstract}

Disclosure: Nothing to report.

If you wish to receive credit for this activity, please refer to the website: www.wileyblackwellcme.com.

\section{ACCREDITATION AND DESIGNATION STATEMENT}

Blackwell Futura Media Services designates this journalbased CME activity for a maximum of 1 AMA PRA Category 1 Credit. ${ }^{T M}$. Physicians should only claim credit commensurate with the extent of their participation in the activity.

Blackwell Futura Media Services is accredited by the Accreditation Council for Continuing Medical Education to provide continuing medical education for physicians.

\section{EDUCATIONAL OBJECTIVES}

The objectives need to be changed. Please remove the existing ones, and include these two:

- To describe the correlation between inpatient and outpatient blood pressure measurements.

- To assess the potential benefits of prescribing antihypertensive medication in hospitalized patients with hypertension.

This manuscript underwent peer review in line with the standards of editorial integrity and publication ethics maintained by Journal of Hospital Medicine. The peer reviewers have no relevant financial relationships. The peer review process for Journal of Hospital Medicine is single-blinded. As such, the identities of the reviewers are not disclosed in line with the standard accepted practices of medical journal peer review.
Conflicts of interest have been identified and resolved in accordance with Blackwell Futura Media Services's Policy on Activity Disclosure and Conflict of Interest. The primary resolution method used was peer review and review by a non-conflicted expert.

\section{INSTRUCTIONS ON RECEIVING CREDIT}

For information on applicability and acceptance of CME credit for this activity, please consult your professional licensing board.

This activity is designed to be completed within an hour; physicians should claim only those credits that reflect the time actually spent in the activity. To successfully earn credit, participants must complete the activity during the valid credit period, which is up to two years from initial publication.

Follow these steps to earn credit:

- Log on to www.wileyblackwellcme.com

- Read the target audience, learning objectives, and author disclosures.

- Read the article in print or online format.

- Reflect on the article.

- Access the CME Exam, and choose the best answer to each question.

- Complete the required evaluation component of the activity.

This activity will be available for CME credit for twelve months following its publication date. At that time, it will be reviewed and potentially updated and extended for an additional twelve months. 